\title{
Panton-valentine leukocidin Staphylococcus aureus severe infection in an infant: a case report and a review of the literature
}

\author{
Massimo Luca Castellazzi ${ }^{1}$, Samantha Bosis ${ }^{2 *}$, Irene Borzani ${ }^{3}$, Claudia Tagliabue $^{2}$, Raffaella Pinzani ${ }^{2}$,
} Paola Marchisio ${ }^{2,4}$ and Giada Maria di Pietro ${ }^{5}$

\begin{abstract}
Background: Panton-Valentine leukocidin (PVL) is one of the major virulence factor of Staphylococcus aureus (SA) that might be associated with invasive life-threating infections. A prompt diagnosis and adequate treatment are essential in achieving the best outcome and avoiding serious sequelae. We describe a case of severe invasive PVLSA infection in an infant. A literature review starting from 2010 was also performed in order to discuss clinical presentations, radiological findings, treatment and outcome.

Case presentation: This is a case of a 6-month-old boy who rapidly developed high fever and poor general condition. He was diagnosed as having multiple muscular abscesses, multiple foci of osteomyelitis and bloodstream infections caused by Panton-Valentine leukocidin Methicillin-resistant Staphylococcus aureus. He received intravenous antibiotics and surgical drainage of the abscess with progressive recovery.

Conclusion: Our report highlights the importance of improving awareness of this severe infection, as a prompt diagnosis and adequate manage is essential in order to save life and to prevent serious complications.
\end{abstract}

Keywords: Panton-valentine leukocidin, Staphylococcus aureus, Children, Infection

\section{Background}

Staphylococcus aureus (SA) is one of the major cause of bacterial infections in humans [1].

Panton-Valentine leukocidin (PVL) is an exotoxin that destroys leukocytes and that is secreted by $2-5 \%$ of SA strains [2].

The presence of PVL genes is associated with an increased risk of a more serious infection requiring intensive care, such as necrotising pneumonia, osteomyelitis, septic arthritis, sepsis and multiorgan failure [3].

Due to the potential association with life-threatening and complicated infections, a high suspicion and

\footnotetext{
* Correspondence: samantha.bosis@policlinico.mi.it

${ }^{2}$ Paediatric Highly Intensive Care Unit, Fondazione IRCCS Ca' Granda Ospedale Maggiore Policlinico, Milan, Italy

Full list of author information is available at the end of the article
}

vigilance for a PVL-positive SA (PLV-SA) infection is essential for a prompt diagnosis and for starting an adequate treatment to achieve the best outcome.

We describe a case of an infant with a severe PLV-SA infection and we perform a literature review since 2010 on this topic in paediatric age.

\section{Case presentation}

A 6 month-old male was admitted to our emergency department for fever since 7 days, erythematous non pruritic skin rash on the trunk, vomiting, diarrhoea and cough.

The child in his first 5 months of life reported four hospitalizations: the first because of an episode of apnoea, the second due to an upper respiratory tract infection, the third and the last one because of two episodes

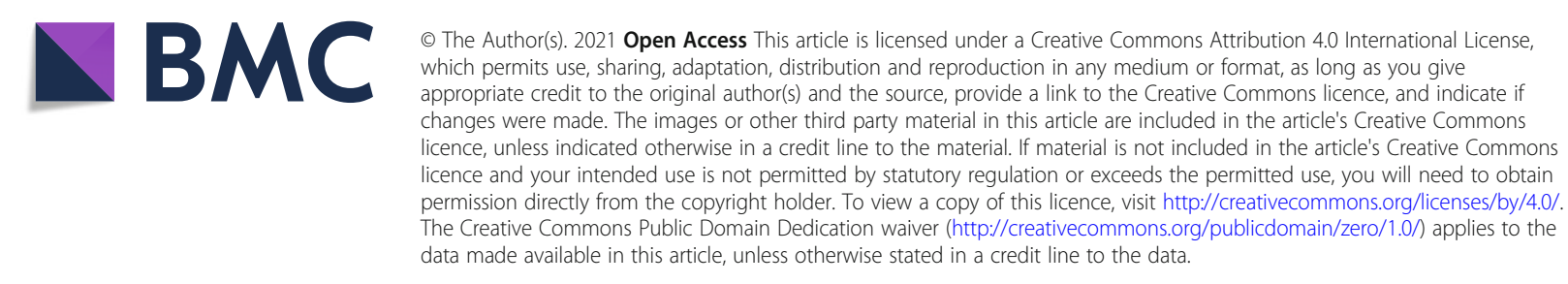


of bronchiolitis. During these hospitalizations, the child performed some immunological investigations which resulted normal and a chest computed tomography (CT) scan that showed a reduced left lower lobe bronchus calibre with accessible segmental and sub-segmental bronchi.

On admission, he was in good general conditions, with normal vital signs, moist mucous membranes, tongue and lips dry, tears when crying, mild tachypnoea (respiratory rate $40 / \mathrm{min}$ ) and wheezes all over the chest. Laboratory tests showed a C-reactive protein (CRP) of $3.5 \mathrm{mg} / \mathrm{dl}$ (normal value $<0.5 \mathrm{mg} / \mathrm{dl}$ ) and a white blood cell count (WBC) of $11,250 / \mu \mathrm{L}$, with $22.9 \%$ of neutrophils. The stool culture, the research of viruses on faeces and isolation of respiratory viruses on nasopharyngeal aspirate were performed and resulted negative. The patient received inhaled bronchodilator and oral steroid therapy with improving of the respiratory symptoms. The child was hospitalized for further investigations for his history of recurrent respiratory infections.

On day three, he performed a bronchoscopy with a bronchoalveolar lavage (BAL). Four days later, the patient's clinical conditions worsened, presenting high fever, clinical signs suggestive of sepsis and a swelling of his left shoulder. He was transferred to the paediatric intensive care unit. The blood tests showed an elevation of CRP $65 \mathrm{mg} / \mathrm{dl}$ and a WBC of $3800 / \mu \mathrm{L}$ with $55 \%$ of neutrophils. A blood culture was also performed. We prescribed a broad spectrum intravenous antibiotic treatment with cefotaxime $100 \mathrm{mg} / \mathrm{kg} /$ day. The echocardiography resulted negative. The abdominal ultrasound showed hepatosplenomegaly.

A contrast-enhanced CT scan of chest and abdomen showed multiple abscesses in the posterior-superior muscles of the shoulder, in the deltoid muscle and in the subscapularis muscle, with pulmonary septic embolisms and fluid collection in the right hip joint. The subsequent whole-body magnetic resonance imaging (WBMRI) confirmed the flogistic findings of the lungs, demonstrated a wide spread of muscular inflammation in almost all the muscle of the upper part of the body with flogistic collections in the muscle around the shoulder and in the left paravertebral muscles of neck. In addition, osteomyelitis of the proximal metaphyseal region of the right femur and the proximal diaphysis of the left humerus was noted (Fig. 1).

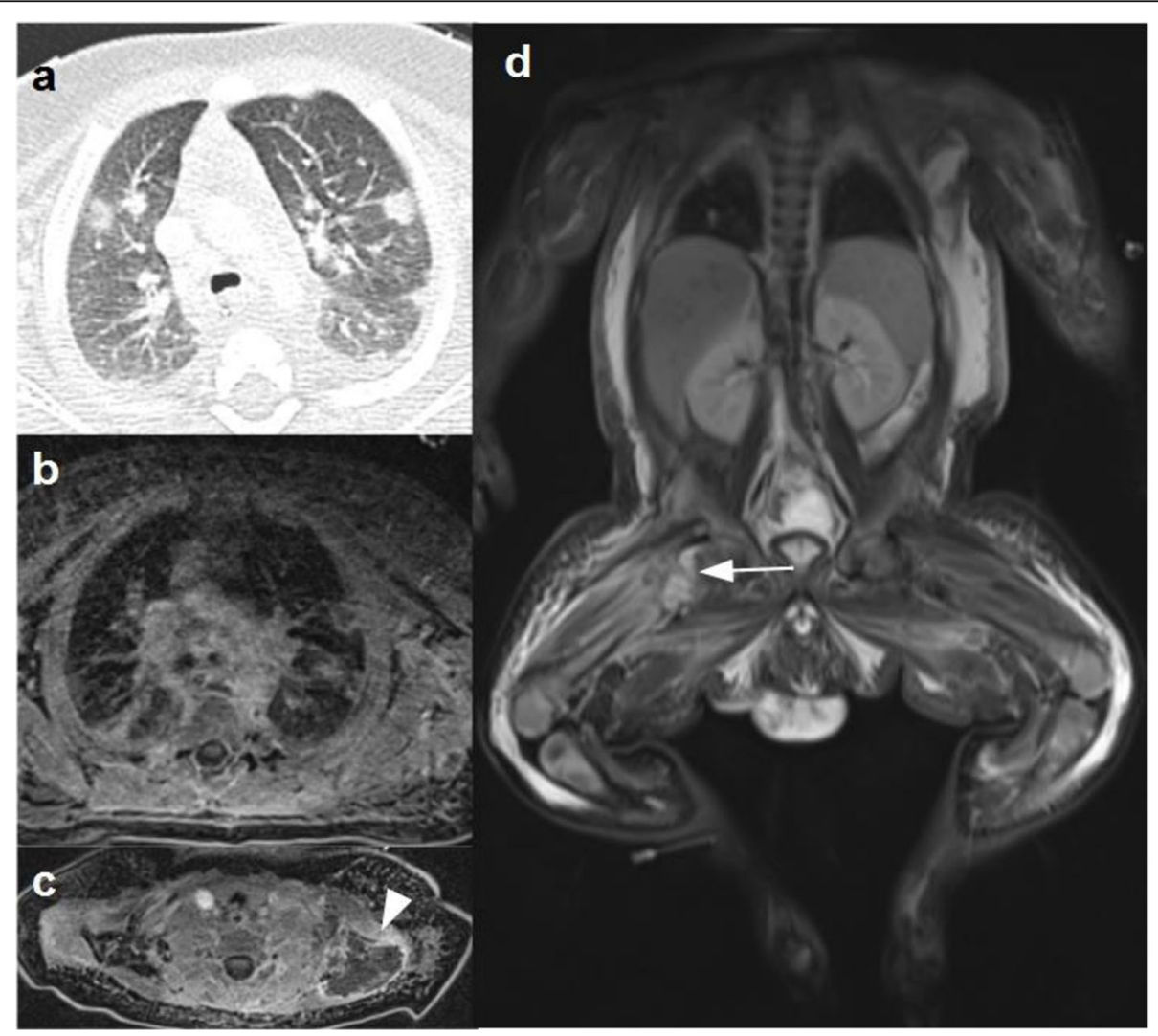

Fig. 1 a-CT and b-Axial T1W-MR image showed scattered lung nodules consisntent with septic emboli. c-Axial T1W-FS MR image with contrast medium showed a huge muscular abscess around the left shoulder (arrowhead). $\mathbf{d}$ - Coronal STIR MR image demonstrated diffuse hyperintense signal of the muscles and the subcutaneous fat throughout the entire body and signal alteration of the right femoral neck associated with right hip effusion (arrow) consistent with osteoarthritis 
The blood culture resulted positive for a MethicillinResistant SA (MRSA), as well the culture of the BAL. The polymerase chain reaction revealed that it was a PVL-MRSA, in particular the ST-121 strain. Of note, also Streptococcus pneumoniae and Haemophilus influenzae were detected in the BAL culture. Therefore, we replaced the antibiotic therapy with a combination of intravenous ceftaroline $24 \mathrm{mg} / \mathrm{kg} /$ day, daptomycin 12 $\mathrm{mg} / \mathrm{kg} /$ day and clindamycin $30 \mathrm{mg} / \mathrm{kg} /$ day. This antibiotic regimen was continued for 2 weeks and then with only intravenous ceftaroline for others 4 weeks. Five days after the start of the triple antibiotic therapy, the infant underwent a surgical drainage of the extended abscess of the left shoulder, and the culture of the purulent exudate resulted positive for the same PVL-MRSA.

There was a gradual normalization of the CRP values and an improvement of symptoms and general conditions. Immunological investigations including immunoglobulins and IgG subclasses, lymphocyte subpopulations and tests for complement function (CH50, AP50) resulted normal. The WB-MRI performed 1 month later showed a resolution of the colliquative area in the muscular tissue, an improvement of the bone structure and oedema of the left humerus and the right femur, a reduction of the focal lung lesions with persistence of pleural thickening (Fig. 2).

He was discharged in good general conditions after 7 weeks of hospital stay with oral linezolid $30 \mathrm{mg} / \mathrm{kg} /$ day divided in 3 doses for 2 weeks.

In order to eradicate the bacterial colonization, the patient and his close family members received daily bathing with chlorhexidine $2 \%$ and intranasal application of mupirocin, because of the positivity of the father's nasal swab for PVL- MRSA.

The WB-MRI performed 6 months later showed a complete radiological resolution.

\section{Discussion and conclusion}

Here we have described a case of a 6-month-old infant with a severe disseminated PVL-MRSA infection with the aim of increasing attention and knowledge on this type of infection, in which a high suspicious is essential for a prompt diagnosis and to start adequate treatment $[4,5]$.

PVL is one of the most important virulence factors of SA and it is encoded by LukS-PV and $L u k F-P V$ genes [6].

PVL may be produced by different strains of SA, in particular both Methicillin-Sensitive SA (MSSA) and MRSA [7]. In a recent multicentre prospective European study the prevalence of PVL-SA amounted to 18,6 and $7,8 \%$ of the isolates were MRSA [8].

Ritz et al. demonstrated that the proportion of PVLSA is higher in infections caused by MRSA (74-100\%) than those caused by MSSA (9-46\%). The proportion is dependent on the prevalence of MRSA in the respective regions [9]. The PVL positivity rate is $77-100 \%$ in community-associated MRSA infections, while it is less than $4 \%$ in hospital-associated MRSA infections [10].

In our patient, the genotype of the PVL-MRSA was ST121, that is, to our knowledge, the first reported in a paediatric patient in Italy. This PVL-SA ST121 strain has been described in literature as mainly disseminated in Africa, Asia and Europe [11].

PVL toxin determines a pore formation in the cytoplasmatic membranes, resulting in leucocyte destruction, tissue necrosis and it contributes to the inhibition of infection clearance by the host immune-system [12]. Therefore, PVL-SA associated infections may be more aggressive and life-threatening. In a retrospective study of Hardy et al., among the six patients with PVL-SA bone and joint infections, there were 2 cases of necrotizing pneumonia, 2 cases of pericarditis and 1 death caused by cardiac tamponade. The microorganism isolated was always a MSSA, due to the low rate of MRSA in the paediatric population of the geographic area where the study was conducted [13]. Recently, in a retrospective study by Hoppe et al. of the 75 children treated for PVL-SA infections, 10 contracted a severe infection including necrotizing pneumonia, necrotizing fasciitis, pyomyositis, mastoiditis with cerebellitis, preorbital cellulitis and recurrent deep furuncolosis in an immunosuppressed patient; MRSA was detected in 4 cases [14].

Since 2010, we have identified 15 reported cases of paediatric PVL-SA severe infections and Table 1 summarizes the main results of these reports regarding the clinical presentations, radiological findings, treatment and outcome [2-5, 15-23].

Among these reports, only Montagnani et al. described 3 cases of severe PVL-SA infection in infants [18]. We have also described the case of severe PVL-SA infection in a 6 month-old infant. Therefore, even though lifethreating infections due to PVL-SA usually occur in older children, we suggest to consider this pathogen also in infants, especially in those with more severe clinical presentation. Furthermore, PVL-SA infection should be suspected in previously healthy young patients with a history of necrotizing skin and soft tissue infections, recurrent abscesses or household cluster infections. Furthermore, it should be suspected in patients with severe musculoskeletal infections and rapidly progressive pneumonia which is usually preceded by a "flu-like" syndrome and in those children with high fever, leukopenia and increased inflammatory markers [18].

PVL-SA strains can be identified by detection of genes encoding PVL or the toxin itself [9]. Conventional bacterial cultures does not differentiate SA producing or not producing PVL [24]. 


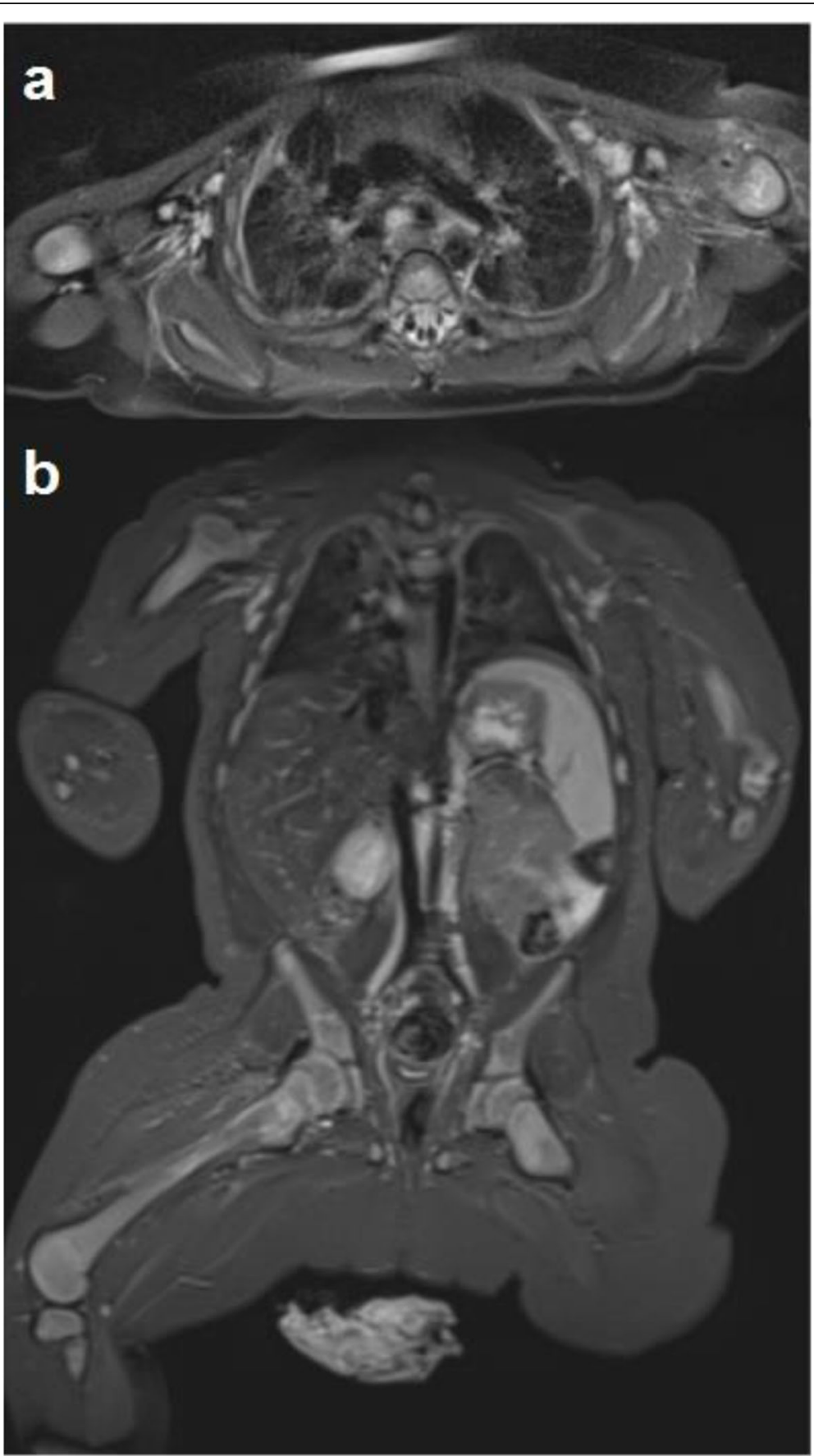

Fig. 2 a-axial and b-coronal STIR MR images performed about 1 month later showed complete resolution of muscular involvement and improvement of lungs and bone flogistic involvement

In our patient WB-MRI was really helpful for the detection and location of multifocal flogistic processes and was a valid and sensitive tool during the follow-up period, without radiation exposure of the child. Wholebody MRI is a fast and accurate modality for detection and monitoring of disease throughout the entire body with a variety of applications in the paediatric patient population [25].
Once diagnosed, PVL-SA infection must be treated appropriately, without delay. Initial empirical coverage generally includes an anti-staphylococcal regimen (amoxicillin-clavulanic acid or flucloxacillin when MSSA is suspected and vancomycin when MRSA is suspected) and, an anti-toxic agent able to block the production of the toxin (clindamycin, rifampicin, linezolid, or gentamicin) $[26,27]$. 


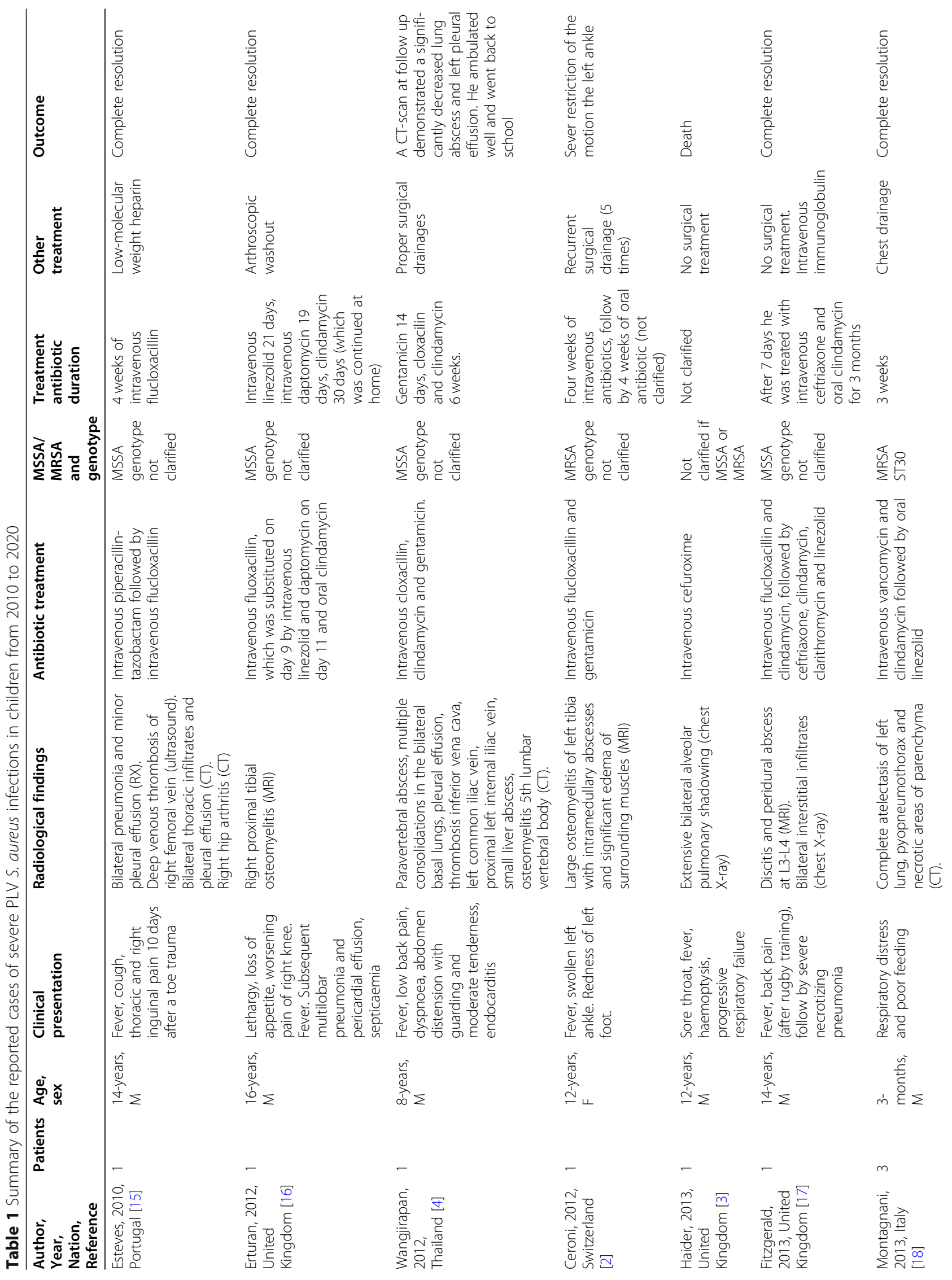




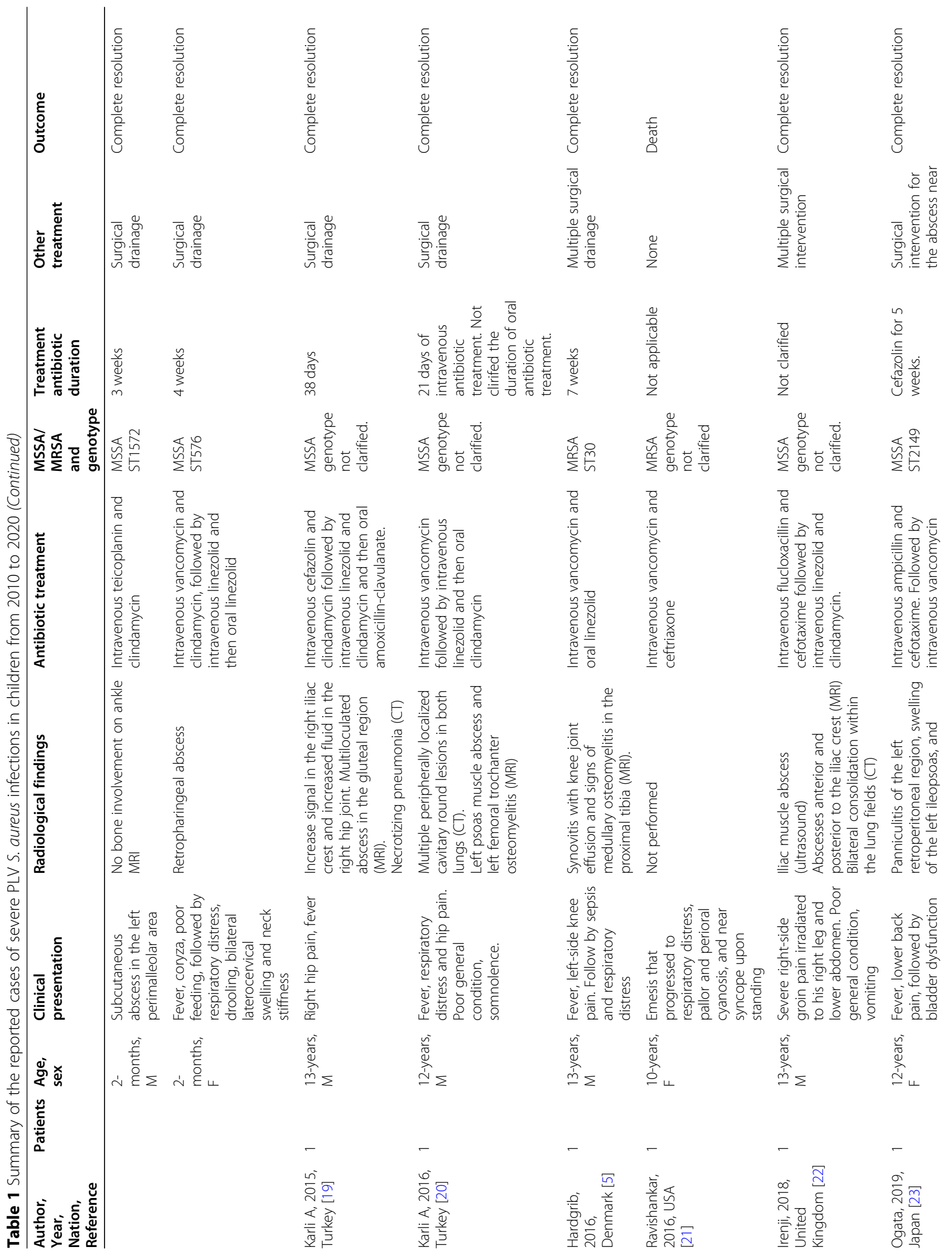




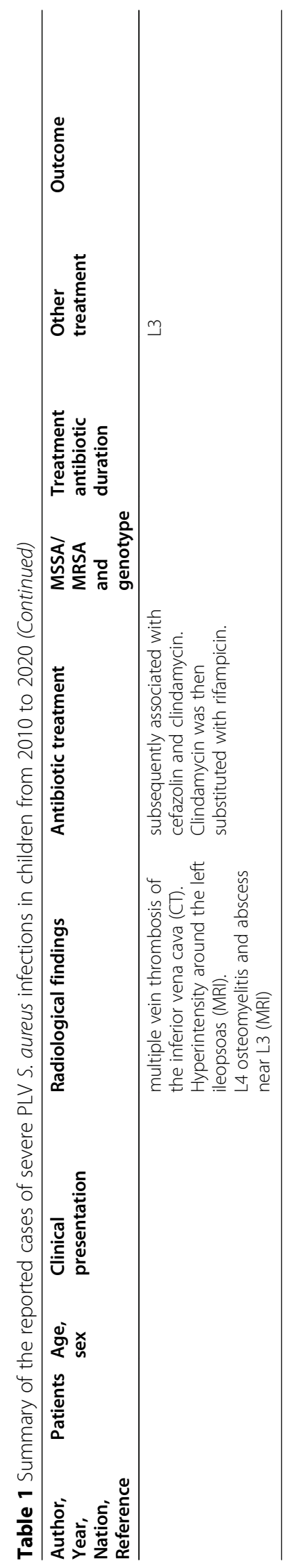


In our case report, the child had a life-threatening infection, community-acquired, in a country with a prevalence of MRSA greater than $10 \%$. We chose ceftaroline as anti-MRSA agent as it is effective and safe similarly to vancomycin $[28,29]$. Furthermore, concentration below the Minimum Inhibitory Concentration of $\beta$-lactams and, to a lesser extent, vancomycin have been shown to enhance PVL secretion, determining more aggressive symptoms [7, 30]. We associated clindamycin, as inhibitor of PVL production. Moreover, in PICU, daptomycin was included in the regimen for the bacteraemia and the osteo-articular infection. This antibiotic regimen was well tolerated by the patient and without adverse reaction. In a recent retrospective study of Syrogiannopoulos et al. it was observed that in children with complicated staphylococcal infections, daptomycin administration alone or in combination with other antimicrobial agents was efficacious and well tolerated [31]. Furthermore, daptomycin was successfully used in 14-year-old boy with tibial osteomyelitis, multilobar pneumonia, pericardial effusion, and septicaemia [16]. In our case, it was an off label use of this antimicrobial agent, introduced due to the severity of the infection.

Generally, a long duration antibiotic therapy is usually needed, in particular in complicated cases [17]. Unfortunately, antibiotic treatment alone is often insufficient, as antibiotic distribution is reduced in necrotic tissue. Surgery plays a major role in achieving a good outcome, with early and complete removal of PVL suppuration from the body and debridement of necrotic tissues. Furthermore, patients with bone and joint infections require more than one surgical procedure [26]. Patients with PVL positive severe infections needed a prolonged hospital stay and a longer recovery times [5].

Decolonisation is part of the process to completely eradicate bacterial colonisation and should involve all household members. Although the optimal eradication strategy for PVL-SA is not known, it is likely to be used the same for MRSA. It includes nasal mupirocin 2\% ointment and chlorhexidine $4 \%$ body wash [27, 32]. In our case, the origin of the infection is not clear, as previous hospitalizations maybe a risk factor. Also his father may have been the source of the infection, as he was an asymptomatic carrier. Surely, the decolonisation therapy, extended to all the family members, brought to the complete eradication of the bacterial colonisation.

In conclusion, this case highlights the importance of considering PLV-SA as the etiologic agent of lifethreatening infection in children. A prompt identification of the toxin is essential in order to start an adequate treatment, that is based not only on prolonged antibiotic treatment but also on surgical drainage in case of abscess or musculoskeletal infection.

\section{Abbreviations}

SA: Staphylococcus aureus; PVL: Panton-Valentine leukocidin; PLV-SA: PantonValentine leukocidin-positive Staphylococcus aureus; CT: computed tomography; CRP: C-reactive protein; WBC: white blood cell; BAL: bronchoalveolar lavage; MRSA: Methicillin-Resistant Staphylococcus aureus; MSSA: Methicillin-Sensitive Staphylococcus aureus; WB-MRI: Whole Body Magnetic Resonance Imaging

\section{Acknowledgements}

Not applicable.

\section{Authors' contributions}

MLC and GMD performed the literature review and wrote the first manuscript. IB performed the radiological studies. CT and RP contributed to patient management. SB and PM critically revised the manuscript and supervised patient management. All the authors read and approved the final version of the manuscript.

\section{Funding}

This case report was supported by the Italian Ministry of Health (Ricerca Corrente 2021 438/03).

\section{Availability of data and materials}

Data sharing was not applicable to this case report because no datasets were generated or analysed during the study.

\section{Declarations}

Ethics approval and consent to participate

Not applicable, as it is a case report.

\section{Consent for publication}

Written informed consent for the publication of this case report was obtained from the patient's parents. A copy of the written consent is available for review by the Editor-in-Chief of this journal.

\section{Competing interests}

The authors declare that they have no competing interests.

\section{Author details}

'Paediatric Emergency Department, Fondazione IRCCS Ca' Granda Ospedale Maggiore Policlinico, Milan, Italy. ${ }^{2}$ Paediatric Highly Intensive Care Unit, Fondazione IRCCS Ca' Granda Ospedale Maggiore Policlinico, Milan, Italy. ${ }^{3}$ Radiology Unit - Paediatric Division, Fondazione IRCCS Ca' Granda Ospedale Maggiore Policlinico, Milan, Italy. ${ }^{4}$ Department of Pathophysiology and Transplantation, University of Milan, Milan, Italy. ${ }^{5}$ University of Milan, Milan, Italy.

Received: 2 February 2021 Accepted: 8 June 2021

Published online: 17 July 2021

\section{References}

1. Kaushik A, Kest H. Pediatric methicillin-resistant Staphylococcus aureus Osteoarticular infections. Microorganisms. 2018;6(2):40. https://doi.org/10.33 90/microorganisms6020040.

2. Ceroni D, Anderson de la Llana R, Zand T, Lamah L, Dominguez D, De Coulon $\mathrm{G}$, et al. Spontaneous tibiotalar arthrodesis as a complication of acute tibial osteomyelitis due to Panton-Valentine leukocidin-producing Staphylococcus aureus: a case report. J Med Case Rep. 2012;6(1):202. https:// doi.org/10.1186/1752-1947-6-202.

3. Haider S, Wright D. Panton-Valentine leukocidin Staphylococcus causing fatal necrotising pneumonia in a young boy. BMJ Case Rep. 2013;2013: bcr2012007655. https://doi.org/10.1136/bcr-2012-007655.

4. Wangjirapan A, Kongthavonsakul K, Oberdorfer P. An 8-year-old boy with severe disseminated Staphylococcus aureus infection. BMJ Case Rep. 2012; 2012:bcr2012007398. https://doi.org/10.1136/bcr-2012-007398.

5. Hardgrib N, Wang M, Jurik AG, Petersen K. Life-threatening MRSA sepsis with bilateral pneumonia, osteomyelitis, and septic arthritis of the knee in a previously healthy 13-year-old boy: a case report. Acta Radiol Open. 2016; 5(10):2058460116677180. https://doi.org/10.1177/2058460116677180. 
6. Karmakar A, Jana D, Dutta K, Dua P, Ghosh C. Prevalence of Pantonvalentine Leukocidin gene among community acquired Staphylococcus aureus: a real-time PCR study. J Pathog. 2018;2018:4518541-8. https://doi. org/10.1155/2018/4518541.

7. Albiński MK, Lutz N, Ceroni D, N'Dele D, Zambelli PY, Bregou A. Paediatric musculoskeletal infections with Panton-valentine leucocidin. Swiss Med Wkly. 2018;148:w14669. https://doi.org/10.4414/smw.2018.14669.

8. Gijón M, Bellusci M, Petraitiene B, Noguera-Julian A, Zilinskaite V, Sanchez Moreno $P$, et al. Factors associated with severity in invasive communityacquired Staphylococcus aureus infections in children: a prospective European multicentre study. Clin Microbiol Infect. 2016;22(7):643.e1-6. https://doi.org/10.1016/j.cmi.2016.04.004.

9. Ritz N, Curtis N. The role of Panton-valentine leukocidin in Staphylococcus aureus musculoskeletal infections in children. Pediatr Infect Dis J. 2012;31(5): 514-8. https://doi.org/10.1097/INF.0b013e31824f18cb.

10. Naimi TS, LeDell KH, Como-Sabetti K, Borchardt SM, Boxrud DJ, Etienne J, et al. Comparison of community- and health care-associated methicillinresistant Staphylococcus aureus infection. JAMA. 2003;290(22):2976-84. https://doi.org/10.1001/jama.290.22.2976.

11. Rao Q, Shang W, Hu X, Rao X. Staphylococcus aureus ST121: a globally disseminated hypervirulent clone. J Med Microbiol. 2015;64(12):1462-73. https://doi.org/10.1099/jmm.0.000185.

12. Shirtliff ME, Mader JT. Acute septic arthritis. Clin Microbiol Rev. 2002;15(4): 527-44. https://doi.org/10.1128/cmr.15.4.527-544.2002.

13. Hardy C, Osei L, Basset T, Elenga N. Bone and joint infections with Staphylococcus aureus strains producing Panton-valentine Leukocidin in French Guiana. Medicine (Baltimore). 2019;98(27):e16015. https://doi.org/10.1 097/MD.0000000000016015.

14. Hoppe PA, Holzhauer S, Lala B, Bührer C, Gratopp A, Hanitsch LG, et al. Severe infections of Panton-valentine leukocidin positive Staphylococcus aureus in children. Medicine (Baltimore). 2019;98(38):e17185. https://doi. org/10.1097/MD.0000000000017185.

15. Esteves I, Castro SV, Abecasis F, Camilo C, Vieira M, da Gama D, et al. Septic pulmonary embolism case report: optimal outcome after insertion of an inferior vena cava filter in a patient with Staphylococcus aureus Bacteraemia. Int J Pediatr. 2010;2010:651023-4. https://doi.org/10.1155/201 0/651023.

16. Erturan G, Holme H, Smith R, Dodds R, lyer S. Successful use of daptomycin in Panton-valentine leucocidin positive Staphylococcus aureus paediatric osteomyelitis. Int J Surg Case Rep. 2012;3(7):238-41. https://doi.org/10.1016/ j.ijscr.2012.03.014.

17. Fitzgerald F, Howard J, Bailey F, Soleimanian S. Back pain in a previously healthy teenager. BMJ Case Rep. 2013;2013:bcr2013200139. https://doi.org/1 0.1136/bcr-2013-200139.

18. Montagnani C, Cocchi P, Bianchi L, Resti M, de Martino M, Galli L. Severe infections caused by Panton-valentine leukocidin-positive Staphylococcus aureus in infants: report of three cases and review of literature. Acta Paediatr. 2013;102(6):e284-7. https://doi.org/10.1111/apa.12225.

19. Karli A, Belet N, Yanık K, Köken Ö, Kılıç M, Ceyhan Bilgici M, et al. Pantonvalentine leukocidin positive Staphylococcus aureus infection in childhood: a case report. Turk J Pediatr. 2015;57(6):615-7.

20. Karli A, Yanik K, Paksu MS, Sensoy G, Aykanat A, Yener N, et al. Disseminated Panton-valentine Leukocidin-positive Staphylococcus aureus infection in a child. Arch Argent Pediatr. 2016;114(2):e75-7. https://doi.org/10.5546/aap.2 016.eng.e75

21. Ravishankar S, Chapin K, Alexander-Scott N, Wills H, Merritt C, Jacobson M, et al. Enterovirus D68 and Panton-valentine Leukocidin-positive Staphylococcus aureus respiratory Coinfection with fatal outcome. Pediatr Dev Pathol. 2016;19(1):80-5. https://doi.org/10.2350/15-06-1652-CR.1.

22. Irenji N, Pillai SKG, West-Jones JS. Serious life-threatening multifocal infection in a child, caused by Panton-Valentine leucocidin-producing Staphylococcus aureus (PVL-MSSA). BMJ Case Rep. 2018;2018:bcr2017222138. https://doi.org/10.1136/bcr-2017-222138.

23. Ogata H, Nagasawa K, Takeuchi N, Hagiwara S, Sawada D, Umimura T, et al. Psoitis and multiple venous thromboses caused by Panton valentine Leukocidin-positive methicillin-sensitive Staphylococcus aureus in a 12-yearold girl: a case report. J Infect Chemother. 2019;25(8):630-4. https://doi. org/10.1016/j.jiac.2019.02.019.

24. Sheikh HQ, Aqil A, Kirby A, Hossain FS. Panton-Valentine leukocidin osteomyelitis in children: a growing threat. Br J Hosp Med. 2015;76(1):18-24. https://doi.org/10.12968/hmed.2015.76.1.18.
25. Ley S, Ley-Zaporozhan J, Schenk JP. Whole-body MRI in the pediatric patient. Eur J Radiol. 2009;70(3):442-51. https://doi.org/10.1016/j.ejrad.2009. 02.012 .

26. Gillet $Y$, Dumitrescu $O$, Tristan A, Dauwalder O, Javouhey E, Floret D, et al. Pragmatic management of Panton-valentine leukocidin-associated staphylococcal diseases. Int J Antimicrob Agents. 2011;38(6):457-64. https:// doi.org/10.1016/j.jjantimicag.2011.05.003.

27. Saeed K, Gould I, Esposito S, Ahmad-Saeed N, Ahmed SS, Alp E, et al. Panton-Valentine leukocidin-positive Staphylococcus aureus: a position statement from the International Society of Chemotherapy. Int J Antimicrob Agents. 2018;51(1):16-25. https://doi.org/10.1016/j.jiantimicag.2017.11.002.

28. Williams AW, Newman PM, Ocheltree S, Beaty R, Hassoun A. Ceftaroline Fosamil use in 2 pediatric patients with invasive methicillin-resistant Staphylococcus aureus infections. J Pediatr Pharmacol Ther. 2015;20(6):47680. https://doi.org/10.5863/1551-6776-20.6.476

29. Sharma R, Hammerschlag MR. Treatment of methicillin-resistant Staphylococcus aureus (MRSA) infections in children: a reappraisal of Vancomycin. Curr Infect Dis Rep. 2019;21(10):37. https://doi.org/10.1007/s11 908-019-0695-4.

30. Dumitrescu O, Badiou C, Bes M, Reverdy ME, Vandenesch F, Etienne J, et al. Effect of antibiotics, alone and in combination, on Panton-valentine leukocidin production by a Staphylococcus aureus reference strain. Clin Microbiol Infect. 2008;14(4):384-8. https://doi.org/10.1111/j.1469-0691.2007. 01947.x.

31. Syrogiannopoulos GA, Michoula AN, Petinaki E, Grivea IN. Daptomycin use in children: experience with various types of infection and age groups. Pediatr Infect Dis J. 2017;36(10):962-6. https://doi.org/10.1097/INF. 0000000000001629

32. Liu C, Bayer A, Cosgrove SE, Daum RS, Fridkin SK, Gorwitz RJ, et al. Clinical practice guidelines by the infectious diseases society of america for the treatment of methicillin-resistant Staphylococcus aureus infections in adults and children: executive summary. Clin Infect Dis. 2011;52(3):285-92. https:// doi.org/10.1093/cid/cir034.

\section{Publisher's Note}

Springer Nature remains neutral with regard to jurisdictional claims in published maps and institutional affiliations.

Ready to submit your research? Choose BMC and benefit from:

- fast, convenient online submission

- thorough peer review by experienced researchers in your field

- rapid publication on acceptance

- support for research data, including large and complex data types

- gold Open Access which fosters wider collaboration and increased citations

- maximum visibility for your research: over $100 \mathrm{M}$ website views per year

At $\mathrm{BMC}$, research is always in progress.

Learn more biomedcentral.com/submissions 